\title{
The Effect of Grinding Media on Mineral Breakage Properties of Magnetite Ores
}

\author{
Liang Si $\mathbb{D}$, Yijun Cao $\mathbb{D}$, and Guixia Fan $\mathbb{C}$ \\ School of Chemical Engineering, Zhengzhou University, Zhengzhou 450000, Henan, China \\ Correspondence should be addressed to Yijun Cao; yijuncao@126.com
}

Received 18 October 2021; Accepted 6 November 2021; Published 11 December 2021

Academic Editor: Minzhong Gao

Copyright $\odot 2021$ Liang Si et al. This is an open access article distributed under the Creative Commons Attribution License, which permits unrestricted use, distribution, and reproduction in any medium, provided the original work is properly cited.

\begin{abstract}
The breakage and liberation of minerals are the key to fluidized mining for minerals. In the ball milling process, steel balls function as not only a grinding action implementer but also energy carrier to determine the breakage behavior of ores and the production capacity of the mill. When ground products present a much coarse or much fine particle size distribution, the separation process will suffer, resulting in inefficient recovery of useful minerals. Optimal control of the particle size distribution of the products is therefore essential, but the complexity and randomness of ball mill grinding make it difficult to determine the appropriate ball size. To solve the problem in the precise measurement of grinding ball diameters, this paper carried out magnetite grinding experiments with grinding balls of different diameters under the same grinding conditions to study the influence pattern of steel ball diameters on the particle break behavior, the particle size distribution of ground products, and the mineral liberation degree distribution. The research proposed on the matching relation between the ball size and the quality of ground products is essential for improving the ground product quality and reducing energy consumption.
\end{abstract}

\section{Introduction}

The efficiency of mineral separation and utilization is part of the research in the fluidized mining technology, and the breakage and liberation of minerals are the key to the efficiency of mineral utilization [1]. When ores containing useful minerals are being processed by relevant equipment and methods, valuable minerals are liberated from gangue minerals [2]. In the whole production process of a beneficiation plant, breakage and grinding are the steps to reduce particle sizes, providing selected materials for the subsequent classification operation to fully liberate useful minerals and make them meet the particle size separation requirements [3]. Grinding operation plays a significant role the national economy, with the cost of breakage and grinding accounting for about $60 \%$ of the total investment in a beneficiation plant, and their power consumption accounting for 50$60 \%$ [4]. More than 5\% of total annual power generation and millions of tons of steel are consumed in ore grinding every year [5]. Ball milling uses steel balls to realize grinding effect, that is, to achieve the ore particle comminution through impact and abrasion with steel balls, and plays an important role in the production of a beneficiation plant. Although it has many advantages, including large reduction ratio, good breakage effect, and strong applicability, [6], there are drawbacks in it at the same time, such as low efficiency, large consumption of steel balls, and serious liner wear [7]. Meanwhile, the ball milling process affects the technical index and economic benefit of a beneficiation plant. Therefore, it is of practical significance to reduce the beneficiation cost and improve the separation index by optimizing the grinding process and selective grinding [8].

Grinding is used to primarily liberate useful minerals and secondarily provide fine ores with a proper particle size for separation. Gaudin [9] developed a mineral liberation model for breakage, but it considered materials only as cubes of equal volumes in an excessively simplified mineral mosaic relation. In some literature, a number of mineral liberation models for breakage were constructed based on the assumption of random fracture, which greatly simplified the algorithms [10]. However, it has been recognized that there is a degree of nonrandomness in the process of breaking [11]. Bérubé and Marchand [12] broke iron ores in different ways including jaw breakage, roller breakage, and ball milling and 
concluded that the particle size distribution and mineral liberation degree were barely different below $210 \mu \mathrm{m}$. Wightman et al. [13] conducted liberation degree analysis on porphyry copper ores and silver-lead-zinc ores broken by rod mill, hammer mill, and piston mold, respectively, concluding that the mineral liberation degree under different particle size distributions was constant, regardless of the type of ore breakage. Vizcarra [14] conducted granular-bed breakage by impact and compression breakage, respectively, in the hammer mill and piston-die press tests. The mineral liberation characteristics of particles determined by mineral liberation analyzer (MLA) are independent from the breakage methods used to produce them. Besides, the difference in particle sizes does not influence the mineral liberation characteristics. Ozcan and Benzer [15] reached the same experimental conclusion that there will be little difference in the mineral liberation degree between the impact and compression breakage when the particle size is $75 \mu \mathrm{m}$. Mariano and Evans [16] studied different types of impact energy on pyrite and copper sulfide ores by using JK Rotary Breakage and found that no impact energy had a significant effect on the mineral liberation degree at a given breakage particle size.

Due to the high consumptions of energy and materials by ball milling, it is necessary to avoid useless grinding. Overbreakage will result in the loss of valuable minerals, low recovery rate, increased wear of equipment, and reduced processing capacity, as well as the waste of flotation reagents [17]. In the process of ball milling, the enhanced liberation of selective minerals and reduced content of overbroken materials are conducive to homogeneous product particle size and further improve the technical index of classification operation [18]. The steel ball size determines the quality of ground products and affects the power and steel consumption of grinding [19]. Therefore, the steel ball size is a key factor in grinding and is crucial to the milling efficiency [20]. Currently, there have been many formulas used to calculate the diameter of steel balls, but there has not been any recognized formula that can be used to calculate the diameter of balls in various grinding media [21]. As the breakage implementer, steel balls are the key to the quality of ground products. As ores are aggregates composed of various minerals, their binding force can result in heterogeneity. Therefore, the type breakage mode is subject to the level of breakage energy needed [22]. The breakage force generated by proper steel balls causes liberation fractures on the mineral interface and then realizes the main purpose of grinding [23].

To study the influence of steel grinding ball sizes on the quality of ground products, this paper used steel balls of 8 different sizes under the same grinding conditions to obtain P80 ground products and analyzed the influence of ball sizes on the particle surface morphology, particle size distribution, and mineral liberation distribution of ground products. Finally, it was proposed to improve the quality of ground products by using grinding balls with a diameter proper for ores to be ground.

\section{Materials and Methods}

2.1. The Sample Preparation. Most of the magnetite ores adopted in this paper had a disseminated particle size

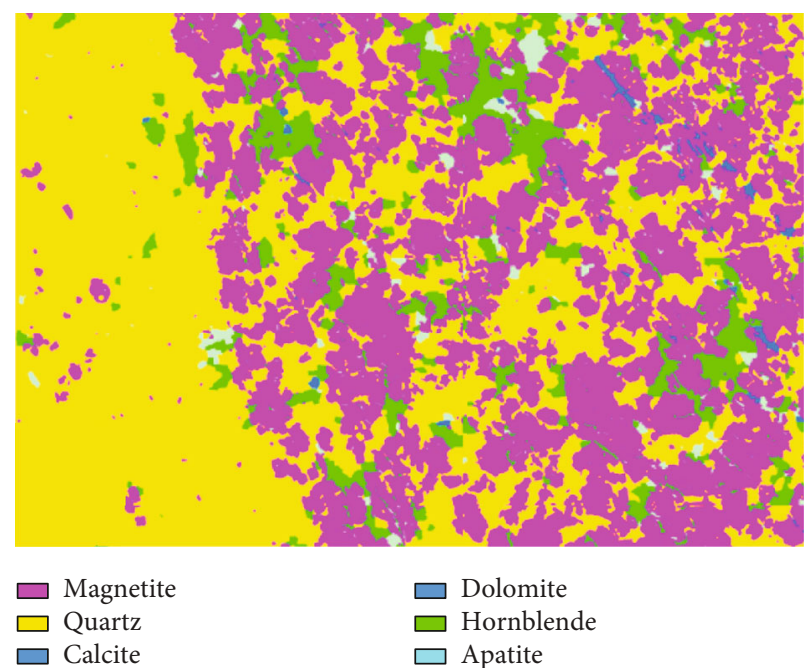

Figure 1: MLA image of the ore sample.

TABLe 1: Raw-ores mineral phases identified by MLA.

\begin{tabular}{lccc}
\hline Mineral & $\begin{array}{c}\text { Mineral weight } \\
(\%)\end{array}$ & $\begin{array}{c}\text { Area ratio } \\
(\%)\end{array}$ & $\begin{array}{c}\text { Particle } \\
\text { number }\end{array}$ \\
\hline Magnetite & 32.48 & 19.8 & 3513 \\
Quartz & 61.73 & 73.97 & 5967 \\
Calcite & 0.26 & 0.30 & 105 \\
Hornblende & 4.56 & 4.41 & 844 \\
\hline
\end{tabular}

smaller than $140 \mu \mathrm{m}$, indicating a fine grain distribution. $80.61 \%$ of magnetite ores have a disseminated particle size smaller than $74 \mu \mathrm{m}$, and $27.21 \%$ have one smaller than $20 \mu \mathrm{m}$. The analysis showed that the dissemination relation between the magnetite minerals was complex and close and that the disseminated particle size of the ores was extremely fine, as shown in Figure 1.

The mineral composition and content are shown in Table 1. According to the measurement result by MLA, the minerals in the ore were mainly magnetite and quartz, accounting for $32.48 \%$ and $61.73 \%$, respectively, and their weight was accounted for $94.21 \%$ of the total, indicating that the magnetite ores can be basically considered a two-phase mineral consisting of magnetite and quartz.

2.2. Grinding Test. In this paper, the wet ball milling process was used in the laboratory ball milling test. Before grinding, the ball mill was kept idle for 10 minutes and then washed together with the grinding media. Three types of ores were crushed and separated by a jaw crusher, and the ground particle size of $-2 \mathrm{~mm}$ was selected. The diameters of the grinding media, i.e., the steel balls, were $10 \mathrm{~mm}, 13 \mathrm{~mm}, 16 \mathrm{~mm}$, $19 \mathrm{~mm}, 22 \mathrm{~mm}, 25 \mathrm{~mm}, 28 \mathrm{~mm}$, and $32 \mathrm{~mm}$, and the weight corresponding to the steel balls of each size was $8107.7 \mathrm{~g}$, $8017 \mathrm{~g}, 8109 \mathrm{~g}, 8095.3 \mathrm{~g}, 8102 \mathrm{~g}, 8106.9 \mathrm{~g}, 8107.7 \mathrm{~g}$, and $8081.1 \mathrm{~g}$, respectively. The mill uses a laboratory hammershaped ball mill, and $500 \mathrm{~g}$ of mineral samples and $300 \mathrm{~g}$ of water are uniformly taken each time with the slurry concentration being $62.5 \%$. The fineness tests were carried out 

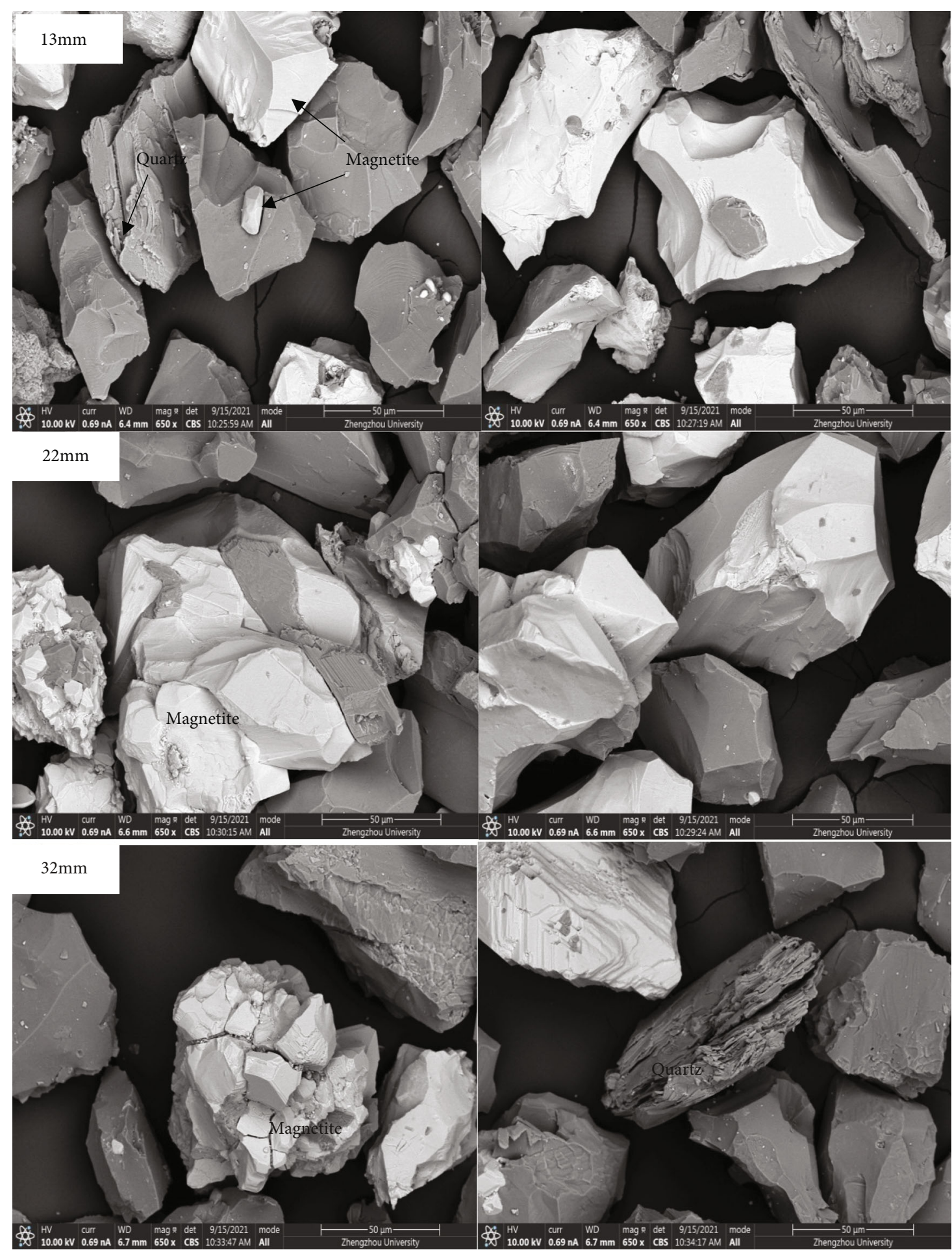

Figure 2: Particles morphology features in different grinding media.

using steel balls of 8 different sizes in laboratory for different grinding periods. Based on the time-fineness curve of the ores obtained through the tests, the grinding particle size was determined to be -200 mesh with a cumulative distribution curve of $80 \%$. The relation between the particle size distribution and the mineral liberation degree at different steel ball sizes was studied to determine the appropriate size of grinding media.
2.3. Mineral Liberation Measurement. To study the effect of steel ball sizes on the mineral liberation characteristics of ground products from the magnetite ores, the mineral liberation degree of ground products with different particle sizes was tested $(-150+75 \mu \mathrm{m},-75+38 \mu \mathrm{m}$, and $-38+20 \mu \mathrm{m})$.

2.4. Particle Size Distribution Test. With the aim of obtaining accurate sieving sizes, the dry sieving method was used for 


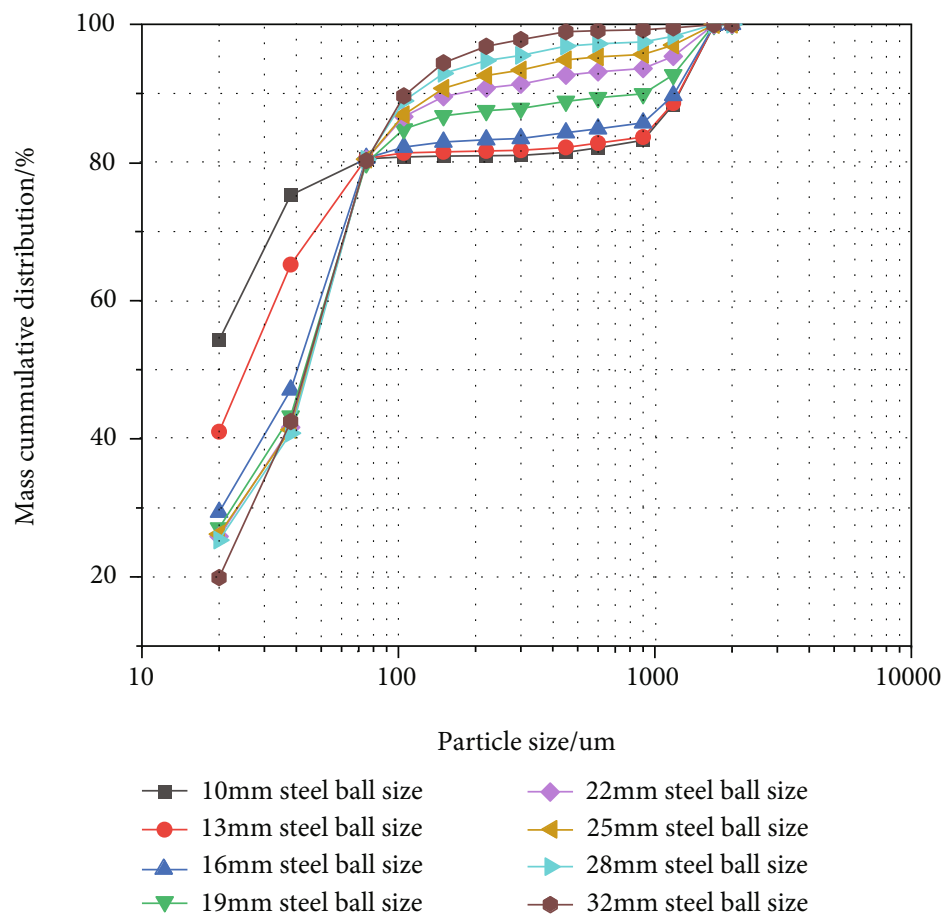

Figure 3: Particle size distribution of products from different steel ball diameters.

$+75 \mu \mathrm{m}$ materials with a standard sieve shaker of knock-on type. Meanwhile, RestschAS200 wet sieving was used for $-75 \mu \mathrm{m}$ materials. A high-precision electronic scale with a measuring range of $1 \mathrm{~kg}$ and the accuracy of $0.01 \mathrm{~g}$ was used to measure weight.

\section{Results and Discussion}

3.1. Particles Surface Morphology. The particle breakage appearance, which records the whole process of mineral cracking under the action of ball milling media, is the surface formed after ores are fractured by the ball milling process,. A fracture occurs in the breakage area when the breakage strength of ores is reached by the impact of different energies produced by steel balls. The fracture characteristics of particles vary due to the difference in breakage energy, and thus, a profound understanding of those characteristics is helpful to reveal the mechanism of the magnetite fracture process. Magnetite ores are mainly composed of magnetite and quartz, while the microscopic mechanical properties between magnetite and quartz are quite different. Additionally, the microscopic fracture appearance of every mineral component is also different under the breakage energy produced by steel balls of various sizes.

The fracture morphology of $-75+20 \mu \mathrm{m}$ particles that were ground by steel balls of three different diameters was analysed, as shown in Figure 2. It was found that the types of magnetite fracture were mainly transgranular fracture and intergranular fracture. The particle fracture appearance of the ores ground with the steel balls of three sizes was mainly brittle fracture. The magnetite particles ground with $32 \mathrm{~mm}$ steel balls demonstrated obvious transgranular fracture compared to those ground with $13 \mathrm{~mm}$ and $22 \mathrm{~mm}$ steel balls. The fracture morphology of quartz minerals included the patterns of shell fracture, river fracture, and flake fracture, which indicated that the breakage energy produced by $32 \mathrm{~mm}$ steel balls was high and that the ground particles had transgranular fracture. The fracture behavior was proved to be unselective, resulting in poor selectivity.

3.2. Particle Size Distribution Test. The particle size distribution of ground products is a key index that directly affects the subsequent separation process. Since the recovery rate in the separation process is affected by both unliberated and overground particles, the quality of ground products can be directly improved by using steel balls of a size proper for the particle size composition characteristics of materials to be ground.

The particle size distribution of ground magnetite products is closely related to the steel ball diameter. The larger the steel ball diameter is, the higher the breakage force will be, and the easier magnetite is to break. As a result, the coarse grade content will be less, and the average particle size of ground products will be smaller. When ground by steel balls of a small size, the ore particles mainly show fatigue fracture, and the coarse-grained ones suffer from poor breakage effect. Figure 3 showed that the mass content of $-20 \mu \mathrm{m}$ magnetite products ground with $10 \mathrm{~mm}$ and $13 \mathrm{~mm}$ steel balls were significantly lower than that of those ground with the steel balls of the other diameters, indicating that the magnetite was seriously over-ground by $10 \mathrm{~mm}$ and $13 \mathrm{~mm}$ steel balls. Although $10 \mathrm{~mm}$ and $13 \mathrm{~mm}$ steel balls had the same weight as the other steel balls and provided smaller breakage force, the products were still seriously overground due to the larger number and higher collision of $10 \mathrm{~mm}$ and $13 \mathrm{~mm}$ steel balls. With the increase of the steel ball 

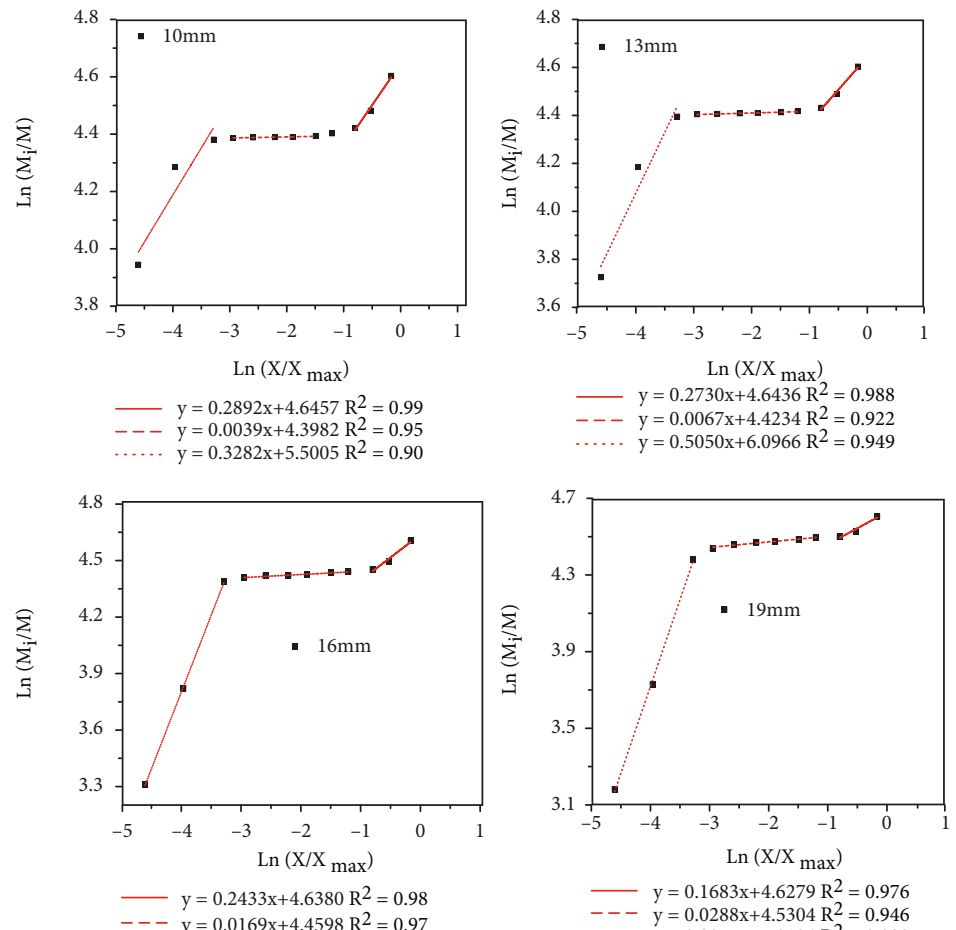

$---y=0.0169 x+4.4598 R^{2}=0.97$

… $\mathrm{y}=0.8159 \mathrm{x}+7.0644 \mathrm{R}^{2}=0.99$

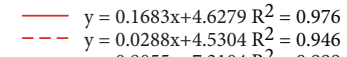

$y=0.0055 x+7.3104 R^{2}=0.999$
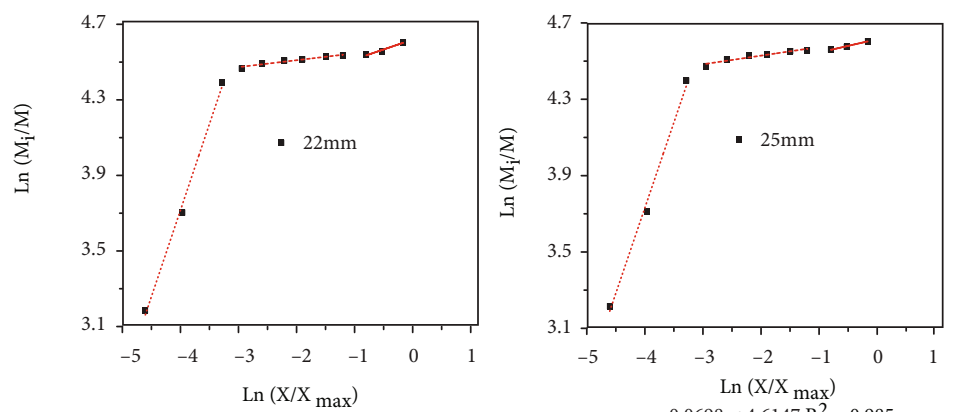

$\mathrm{y}=0.1046 \mathrm{x}+4.6191 \mathrm{R}^{2}=0.974$

$---y=0.0364 x+4.5827 R^{2}=0.939$

… $y=0.9144 x+7.3728 R^{2}=0.996$

$-\mathrm{y}=0.0698 \mathrm{x}+4.6147 \mathrm{R}^{2}=0.985$

$---y=0.0453 x+4.6191 R^{2}=0.932$

… $y=0.8949 x+7.3105 R^{2}=0.994$
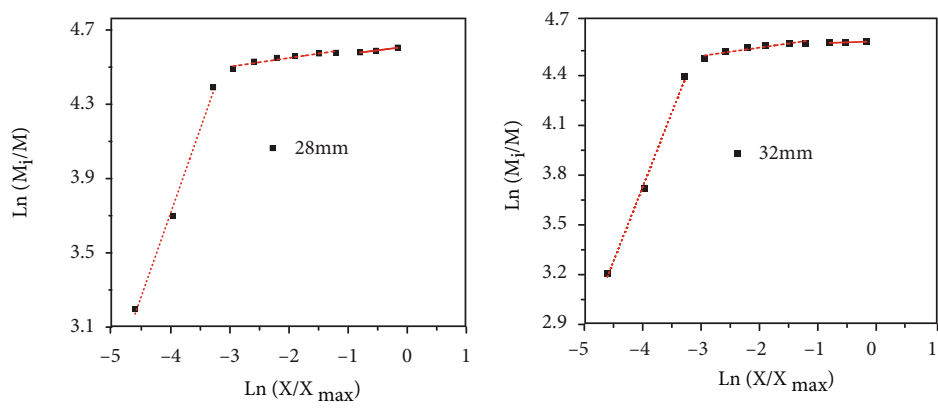

$$
\begin{aligned}
&-y=0.0402 x+4.6106 R^{2}=0.988 \\
&---y=0.0469 x+4.6431 R^{2}=0.909 \\
& \cdots \cdots y=0.9043 x+7.3348 R^{2}=0.994
\end{aligned}
$$

$$
\begin{aligned}
& -y=0.0118 x+4.6065 R^{2}=0.996 \\
& --y=0.0501 x+4.6689 R^{2}=0.870 \\
& \cdots \cdots y=0.8664 x+7.2104 R^{2}=0.992
\end{aligned}
$$

FIGURE 4: Multifractal analysis of magnetite grinding products by steel balls of different sizes.

diameter, the yield of fine particles was first decreased and then increased. When the ball diameter reached $28 \mathrm{~mm}$ and $32 \mathrm{~mm}$, the impact force was higher, but the number of balls was decreased, resulting in low particle breakage. It indicated that the particle size of ground products was increased when the steel ball diameter was so large that it caused excessive breakage force and overgrinding. Therefore, overgrinding would always occur when the ball diameter was either too small or too large, leaving ground products too fine or too coarse. A qualified particle size must be 
obtained during grinding, or the subsequent separation process will be affected due to improper particle size of ground products. When $-75+20$ um was selected as the particle size for qualified ground products, the particle size distribution of the qualified ground magnetite particles reached a value as high as $22 \mathrm{~mm}$ and accounted for $54.57 \%$ of the total based on the ground particle size composition. The proper ball size for different materials to be ground can be various, and their yield of qualified ground products will be maximized when the proper ball size is adopted.

\subsection{Multifractal of Particle Size Distribution of Grinding} Products. For breakage equipment, such as jaw crushers and cone crushers, a section of a fractal is enough to fully reflect the fractal characteristics of crushed materials. For high energy consumption breakage equipment such as ball mills, however, it is more proper to use a multifractal to measure the particle size distribution. Therefore, it is impossible to completely control the whole particle size distribution range with only a single fractal number. A multifractal is used to describe the particle size distribution characteristics after breakage with many multifractal parameters, which can be used to accurately analyze the characteristics of particle size distribution after grinding. The particle size distribution of ground products has a certain range and shows the characteristics of partial fractals. The value of different fractal dimensions $D$ can be observed in different particle size ranges. To study the influence of different steel ball diameters on the particle size distribution after comminution, the particle sizes are divided into three categories, including coarse particles, medium fine particles, and fine particles. The ground particle size presents different fractal dimensions in these three categories, respectively. The formula below is used to calculate the fractal dimensions of the three categories of ground particle sizes:

$$
\begin{aligned}
\ln \left[\frac{M(<r)}{M_{T}}\right]= & \left(3-D_{1}\right) \ln r+c_{1}\left(<\ln d_{a}\right)+\left(3-D_{2}\right) \ln r \\
& +c_{2}\left(<\ln d_{a}\right)+\left(3-D_{3}\right) \ln r+c_{3}\left(<\ln d_{b}\right) .
\end{aligned}
$$

In this formula, $r$ represents the particle size and $d_{a}$ and $d_{b}$ are particle size values at the inflection point of the curve, representing the score point of coarse particles and medium fine particles, and the break point of medium fine particles and fine particles, respectively. $D_{1}, D_{2}$, and $D_{3}$ represent the fractal dimensions of particle size distribution for the coarse particle, medium fine particle, and fine particle categories, respectively. $c_{1}, c_{2}$, and $c_{3}$ are constants.

The three-section fractal linear fitting curves of particle sizes corresponding to the steel balls of different diameters after magnetite grinding and breakage are shown in Figure 4 . The three-section fractal dimension results of particle size distribution corresponding to the steel balls of different diameters are shown in Table 2. Based on the correlation coefficient of the fitting line, the three-section fractal model can describe more accurately the characteris-
TABle 2: The third-stage fractal dimension of magnetite particle size distribution by grinding.

\begin{tabular}{lccc}
\hline $\begin{array}{l}\text { Steel ball } \\
\text { diameter/ } \\
\mathrm{mm}\end{array}$ & $\begin{array}{c}\text { Coarse particle } \\
\text { fractal } \\
\text { dimension }\end{array}$ & $\begin{array}{c}\text { Medium particle } \\
\text { fractal dimension }\end{array}$ & $\begin{array}{c}\text { Fine particle } \\
\text { fractal } \\
\text { dimension }\end{array}$ \\
\hline 10 & 2.7108 & 2.9961 & 2.6718 \\
13 & 2.7270 & 2.9933 & 2.4950 \\
16 & 2.7567 & 2.9831 & 2.1841 \\
19 & 2.8317 & 2.9712 & 2.0945 \\
22 & 2.8954 & 2.9636 & 2.0856 \\
25 & 2.9302 & 2.9547 & 2.1051 \\
28 & 2.9598 & 2.9531 & 2.0957 \\
32 & 2.9882 & 2.9499 & 2.1336 \\
\hline
\end{tabular}

tics of particle size distribution produced by steel balls of different diameters.

The fractal change of particle sizes produced by steel balls of different diameters after magnetite grinding is shown in Figure 5. In the coarse particle size range of $-2000+600$ $\mu \mathrm{m}$, when the steel ball diameter was 10 to $32 \mathrm{~mm}$, the fractal dimension of the coarse particles gradually increased with the increase of the steel ball diameters. In the medium fine particle size range of $-600+105 \mu \mathrm{m}$, the fractal dimension of the particle sizes decreased gradually with the increase of the steel ball diameters. In the fine particle size range of $-75+20 \mu \mathrm{m}$, when the steel ball diameter was 10 to $22 \mathrm{~mm}$, the fractal dimension of the particle sizes decreased greatly with the increase of the steel ball diameters. The inflection point of the fractal dimension of the particle sizes appeared at the steel ball diameter of $22 \mathrm{~mm}$. When the steel ball diameter was 22 to $28 \mathrm{~mm}$, the fractal dimension of the particle sizes showed minor changes. Hence, it demonstrated that the larger the size of the steel balls was, the less influence the steel balls had on the comminution degree of fine particles.

According to the fractal analysis of the three sections of magnetite ground by steel balls of different diameters, the fractal dimension of the coarse and medium fine particles of ground magnetite products was between 2.00 and 3.00, and energy was consumed between the volume and the surface in the grinding process. In the fine particle size range of $-75 \mu \mathrm{m}$, the fractal dimension of particle sizes decreased, indicating that more energy was consumed on the fine particles with an increasing proportion, which means that more energy input from grinding was consumed on the new surfaces, and thus $D_{3}$ gradually approached 2. At this time, the breakage mechanism can be deemed as the transgranular fracture of magnetite, and therefore, the energy consumption is the highest in the fine particle breakage process. As a result, the particle fracture mode was changed from crack propagation among particles to shear slip within the particles in the fine particle size range of $-75+20 \mu \mathrm{m}$. In this process, the fractal dimension of particle size distribution gradually decreased while the energy consumption gradually increased. The fractal dimension change can clearly 

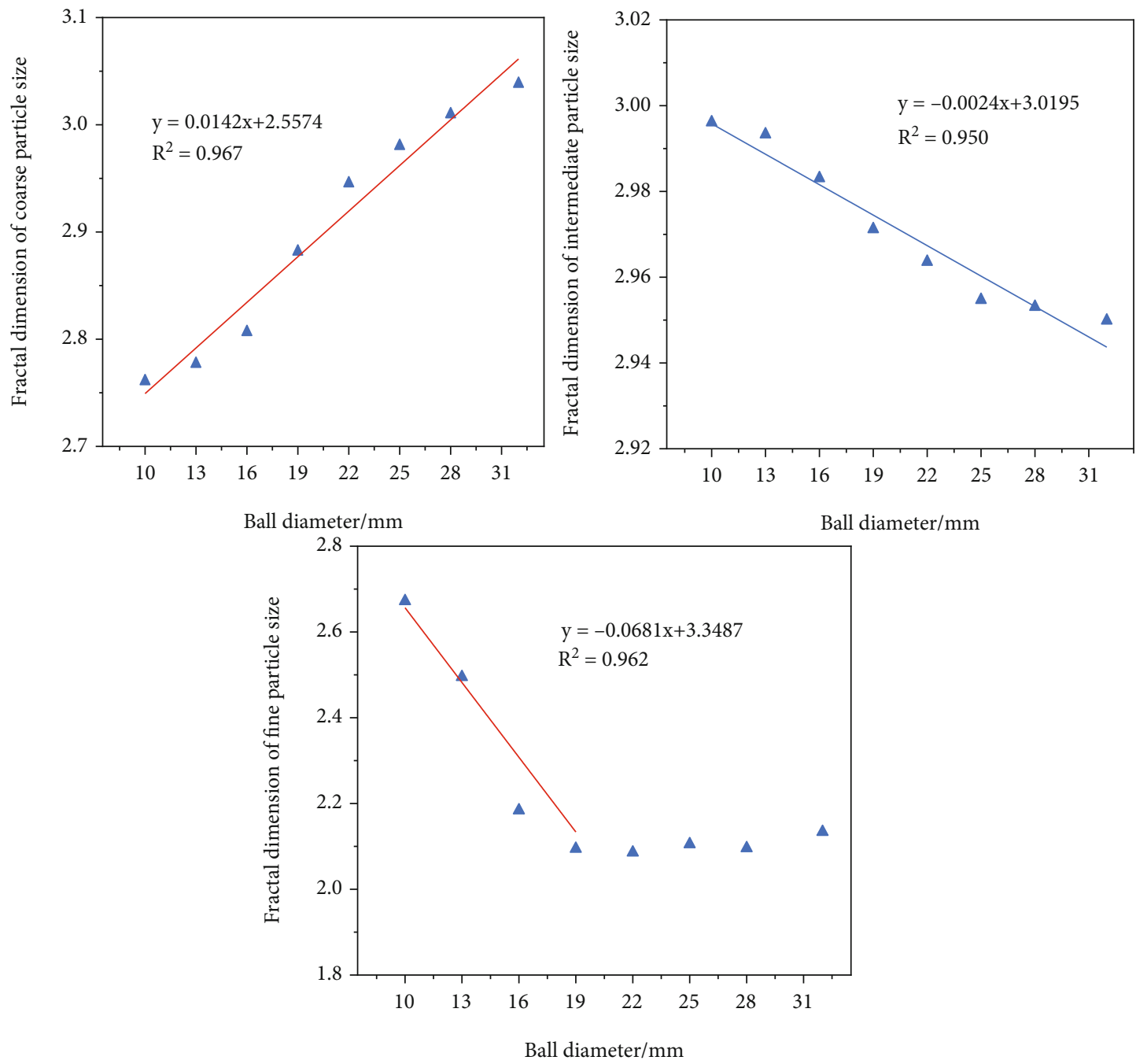

Figure 5: The relationship between the steel ball sizes and the fractal dimensions of different particle size distribution by grinding.

represent the trend of energy consumption in the ore particle breakage process using steel ball of different diameters, i.e., the smaller the fractal dimension is, the more energy the process consumes, and the more difficult it is to crush particles.

3.4. Liberation Properties. Ore grinding is mainly used to liberate valuable minerals from gangue minerals, and thus, the grinding product quality is evaluated mainly based on the mineral liberation degree. MLA analysis was carried out to determine the mineral liberation degree of the ground magnetite products by steel balls of different diameters.

The liberation distribution degrees of qualified ground product particle size of $-75+38 \mu \mathrm{m}$ and $-38+20 \mu \mathrm{m}$ produced by steel balls of different sizes are, respectively, shown in Figure 6 and Table 3. Some magnetite particles were incompletely liberated, and others were still intergrown. The breakage force was small when the diameter of the steel balls was $10 \mathrm{~mm}$ and $13 \mathrm{~mm}$, the breakage force was law, and the breakage mode on the surface caused by grinding was mainly partial fatigue fracture. Therefore, the mineral liber- ation degree of magnetite produced with $10 \mathrm{~mm}$ and $13 \mathrm{~mm}$ steel balls was better than those by the other ones. However, the grinding efficiency was low since the diameter of the steel balls was small. Additionally, the particle size distribution of the ground products was characterized as higher at the large and small sizes and lower at the medium sizes. It was concluded that the steel balls of $10 \mathrm{~mm}$ and $13 \mathrm{~mm}$ were inappropriate. When the steel balls ranging from $16 \mathrm{~mm}$ to $22 \mathrm{~mm}$ were used for grinding, there was change in the mineral liberation, which suggested that the mineral liberation degree remained stable under a certain range of energy generated by the grinding media. When the diameter of the steel balls was $22 \mathrm{~mm}$, the liberation degree of quartz was low, which met the selective breakage principle, i.e., crushing valuable minerals and reducing gangue mineral breakage. When the diameter of the steel balls was $25-28 \mathrm{~mm}$, the magnetite liberation decreased, while high breakage energy was generated along the direction of the maximum effect of force rather than at the mineral interface with the increase of the steel ball diameters. Therefore, the fracture behavior was not selective and the mineral liberation degree was poor. 


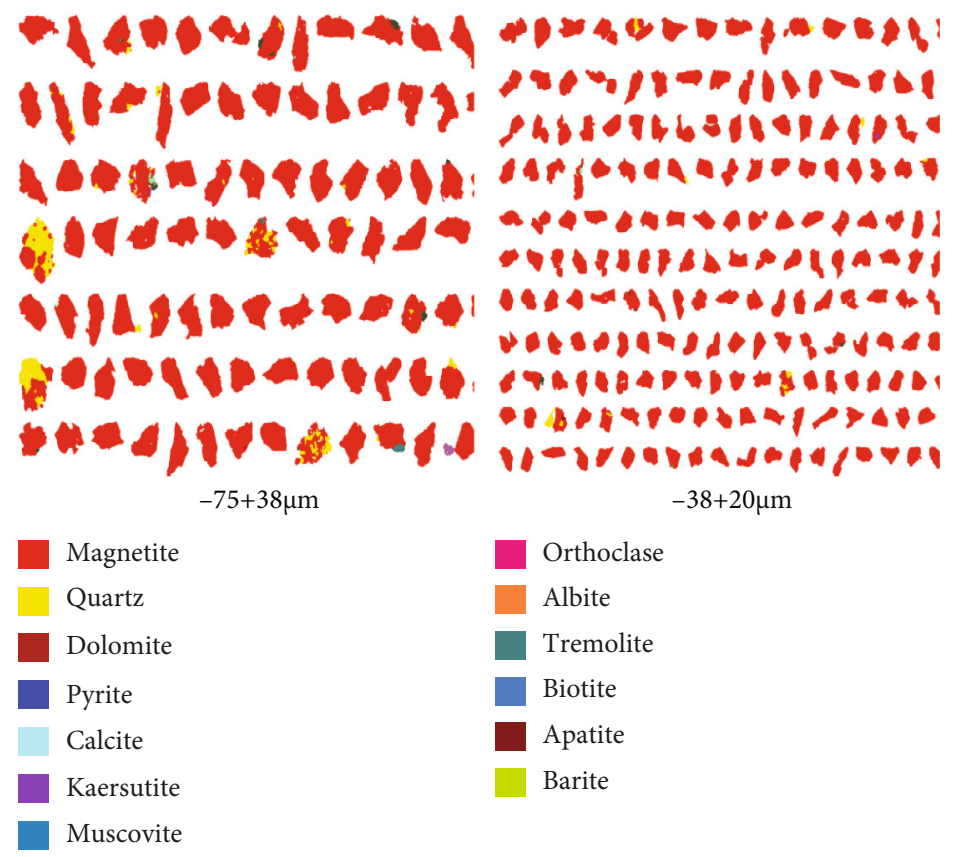

FiguRE 6: MLA image of liberation characteristics of the magnetite ore.

TABLE 3: Liberation degree of qualified magnetite particle size of $-75+20 \mu \mathrm{m}$ by steel balls of different diameters.

\begin{tabular}{|c|c|c|c|c|c|}
\hline \multirow{2}{*}{ Ball diameter } & \multirow{2}{*}{$\begin{array}{l}-75+20 \mu \mathrm{m} \\
\text { Weight }(\%)\end{array}$} & \multicolumn{2}{|c|}{$-75+38 \mu \mathrm{m}$} & \multicolumn{2}{|c|}{$-38+20 \mu \mathrm{m}$} \\
\hline & & Quartz liberation (\%) & Magnetite liberation (\%) & Quartz liberation (\%) & Magnetite liberation (\%) \\
\hline $10 \mathrm{~mm}$ & 26.26 & 58.08 & 71.37 & 76.32 & 82.36 \\
\hline $13 \mathrm{~mm}$ & 39.58 & 63.11 & 79.51 & 83.70 & 92.09 \\
\hline $16 \mathrm{~mm}$ & 53.19 & 42.05 & 67.64 & 75.62 & 88.40 \\
\hline $19 \mathrm{~mm}$ & 55.63 & 49.71 & 66.58 & 76.15 & 88.59 \\
\hline $22 \mathrm{~mm}$ & 56.66 & 41.95 & 65.32 & 77.35 & 90.91 \\
\hline $25 \mathrm{~mm}$ & 56.33 & 42.29 & 65.14 & 79.93 & 90.20 \\
\hline $28 \mathrm{~mm}$ & 56.26 & 42.58 & 65.46 & 77.97 & 89.60 \\
\hline $32 \mathrm{~mm}$ & 55.22 & 38.03 & 47.30 & 80.36 & 90.79 \\
\hline
\end{tabular}

$22 \mathrm{~mm}$ was the proper steel ball diameter that could be used to produce better liberation and qualified particle size for $75+20 \mu \mathrm{m}$ magnetite.

\section{Conclusions}

This paper studied the influence of steel ball sizes on the particle size distribution of ground products, particle surface morphology, and mineral liberation distribution, suggesting that a proper ball diameter was necessary to realize the required quality of ground products, and concluded as follows:

The effect of steel ball diameters on the surface morphology of magnetite was studied. The magnetite crack propagation produced by grinding balls under different energies resulted in a great difference in the particle fracture appearance. The ground products featured a transgranular fracture mode, presenting obvious magnetite crystal cracks.

Based on the particle size distribution of magnetite after grinding in the multifractal method, the connection between the fractal dimensions and the ball diameters was established for the coarse, medium, and fine particles. The result demonstrated that, in the coarse particle size range of $-2000+900$ $\mu \mathrm{m}$, the fracture mode was mainly crack fracture, and the fractal dimension of particle size distribution increased gradually with the increase of the steel ball diameters. In the medium particle size range of $-600+150 \mu \mathrm{m}$, the fracture mode was mainly crack fracture and surface fracture, and the fractal dimension of particle size distribution decreased gradually with the increase of the steel ball diameters. In the fine particle size range of $-75+20 \mu \mathrm{m}$, when the ball diameter was 10 $19 \mathrm{~mm}$, the fractal dimension of particle size distribution decreased gradually with the increase of steel ball diameters, while the fractal dimension of particle size distribution showed minor changes when it was $22-32 \mathrm{~mm}$, indicating that the energy generated by the balls of $22 \sim 32 \mathrm{~mm}$ had negligible influence on the breakage of fine ore particles. Therefore, the multifractal method can be used to evaluate the influence of ball diameters on the particle size distribution.

The relationship between ball diameters and the liberation degree of ground magnetite products was studied. The 
mineral liberation degree under different particle size ranges after grinding showed that the impact energy value generated by a suitable ball diameter liberated and broke the magnetite particles along the interface of different minerals and produced a higher mineral liberation degree for magnetite. Based on the yield of ground products with a qualified particle size and the mineral liberation degree of magnetite, it was determined that $22 \mathrm{~mm}$ was the proper ball diameter.

\section{Data Availability}

All data included in this study are available upon request by contact with the first author.

\section{Conflicts of Interest}

The authors declare that they have no conflicts of interest.

\section{Acknowledgments}

This work was supported by the National nature science foundation of China (No. U1704252), National key research and development program (No. 2018YFC0604702, 2020YFC1908800, and 2018YFC1901601), and Program for Innovative Research Team (in science and technology) in University of Henan Province (No. 19IRTSTHN028).

\section{References}

[1] H. Xie, Y. Ju, F. Gao, M. Gao, and R. Zhang, "Groundbreaking theoretical and technical conceptualization of fluidized mining of deep underground solid mineral resources," Tunnelling \& Underground Space Technology, vol. 67, pp. 68-70, 2017.

[2] R. Sousa, B. Simons, K. Bru et al., "Use of mineral liberation quantitative data to assess separation efficiency in mineral processing - some case studies," Minerals Engineering, vol. 127, pp. 134-142, 2018.

[3] X. Bu, Y. Chen, G. Ma, Y. Sun, C. Ni, and G. Xie, "Wet and dry grinding of coal in a laboratory-scale ball mill: particle-size distributions," Powder Technology, vol. 359, pp. 305-313, 2020.

[4] S. Sadrai, J. A. Meech, M. Ghomshei, F. Sassani, and D. Tromans, "Influence of impact velocity on fragmentation and the energy efficiency of comminution," International Journal of Impact Engineering, vol. 33, no. 1-12, pp. 723-734, 2006.

[5] F. Musa and R. Morrison, "A more sustainable approach to assessing comminution efficiency," Minerals Engineering, vol. 22, no. 7-8, pp. 593-601, 2009.

[6] D. W. Fuerstenau and A. Z. M. Abouzeid, "The energy efficiency of ball milling in comminution," International Journal of Mineral Processing, vol. 67, no. 1-4, pp. 161-185, 2002.

[7] P. W. Cleary, "Charge behaviour and power consumption in ball mills: sensitivity to mill operating conditions, liner geometry and charge composition," International Journal of Mineral Processing, vol. 63, no. 2, pp. 79-114, 2001.

[8] F. Ma, D. Tao, Y. Tao, and S. Liu, "An innovative flake graphite upgrading process based on HPGR, stirred grinding mill, and nanobubble column flotation," International Journal of Mining Science and Technology, vol. 31, pp. 1-12, 2021.

[9] A. M. Gaudin, Principles of Mineral Dressing, McGraw-Hill, New York, N. Y., 1939.
[10] R. P. King, "A model for the quantitative estimation of mineral liberation by grinding," International Journal of Mineral Processing, vol. 6, no. 3, pp. 207-220, 1979.

[11] R. P. King and C. L. Schneider, "Mineral liberation and the batch communition equation," Minerals Engineering, vol. 11, no. 12, pp. 1143-1160, 1998.

[12] M. A. Bérubé and J. C. Marchand, "Evolution of the mineral liberation characteristics of an iron ore undergoing grinding," International Journal of Mineral Processing, vol. 13, no. 3, pp. 223-237, 1984.

[13] E. M. Wightman, C. L. Evans, T. Vizcarra, and G. Sandoval, "Process mineralogy as a tool in modelling mineral processing operations," in 9th International Congress for Applied Mineralogy, pp. 475-481, Brisbane, QLD, 2011.

[14] T. Vizcarra, The effect of comminution mechanism on particle properties: consequences for downstream flotation performance, [Ph.D. thesis], The University of Queensland, 2010.

[15] O. Ozcan and H. Benzer, "Comparison of different breakage mechanisms in terms of product particle size distribution and mineral liberation," Minerals Engineering, vol. 49, pp. 103-108, 2013.

[16] R. A. Mariano and C. L. Evans, "The effect of breakage energies on the mineral liberation properties of ores," Minerals Engineering, vol. 126, pp. 184-193, 2018.

[17] B. Xza, B. Yha, G. Peng, B. Yla, and B. Ysa, "Effects of particle size and ferric hydroxo complex produced by different grinding media on the flotation kinetics of pyrite," Powder Technology, vol. 360, pp. 1028-1036, 2020.

[18] G. J. Jameson, “The effect of surface liberation and particle size on flotation rate constants," Minerals Engineering, vol. 36-38, pp. 132-137, 2012.

[19] X. Zhang, Y. Han, P. Gao, and Y. Li, "Effects of grinding media on grinding products and flotation performance of chalcopyrite," Minerals Engineering, vol. 145, pp. 106070-106079, 2020.

[20] C. Aldrich, "Consumption of steel grinding media in mills - a review," Minerals Engineering, vol. 49, pp. 77-91, 2013.

[21] C. Bazin and P. Obiang, "Should the slurry density in a grinding mill be adjusted as a function of grinding media size?," Minerals Engineering, vol. 20, no. 8, pp. 810-815, 2007.

[22] P. Semsari Parapari, M. Parian, F. Forsberg, and J. Rosenkranz, "Characterization of ore texture crack formation and liberation by quantitative analyses of spatial deformation," Minerals Engineering, vol. 157, article 106577, 2020.

[23] T. Wang, W. Zou, R. Xu et al., "Assessing load in ball mill using instrumented grinding media," Minerals Engineering, vol. 173, pp. 107198-107199, 2021. 